\title{
Spatial patterns of Pinus tabulaeformis and Pinus massoniana forests in Qinling-Daba Mountains and the boundary of subtropical and warm temperate
} zones

\author{
YAO Yonghui ${ }^{1}$, HU Yufan ${ }^{1,2}$, KOU Zhixiang ${ }^{1,2}$, ZHANG Baiping ${ }^{1}$ \\ 1. State Key Laboratory of Resources and Environment Information System, Institute of Geographic Sciences \\ and Natural Resources Research, CAS, Beijing 100101, China; \\ 2. University of Chinese Academy of Sciences, Beijing 100049, China
}

\begin{abstract}
The Qinling Mountains is not only the geographical boundary between North and South China, but also the boundary between subtropical and warm temperate zones. It plays an important role in the geo-ecological pattern of China. However, there is controversy about the specific location of this geographical boundary in academic community due to the complexity, transition and heterogeneity of the transitional zone, as well as the differences in the delimitation indicators and research purposes. To further reveal the characteristics of the North-South transitional zone and clarify the specific location of the geo-ecological boundary between North and South China, combined with SRTM topographic data, temperature and precipitation data, Pinus massoniana forest and Pinus tabulaeformis forest, which represent subtropical coniferous forest in South China and temperate coniferous forest in North China respectively, were chosen to analyze their spatial distributions in the Qinling-Daba Mountains and the climatic conditions at their boundary with the climatic indexes of annual precipitation, the coldest month (January) average temperature, the warmest month (July) average temperature and the annual average temperature. The results show that: (1) Pinus massoniana and Pinus tabulaeformis forests and the climate indicators of their boundary can be used as one of the vegetation-climate indexes for the delimitation of subtropical and warm temperate zones. The boundary between the subtropical coniferous forest (Pinus massoniana forest) and temperate coniferous forest (Pinus tabulaeformis forest) is located along the south slope of Funiu Mountain to the north edge of Hanzhong Basin (the south slope of Qinling Mountains) at an altitude of 1000-1200 m, where the climatic indictors are stable: the annual precipitation is about $750-1000 \mathrm{~mm}$, the annual average temperature is about $12-14^{\circ} \mathrm{C}$, the coldest monthly average temperature is $0-4^{\circ} \mathrm{C}$, and the warmest monthly average temperature is about $22-26^{\circ} \mathrm{C}$. (2) It can be more scientifically to delimitate the boundary of subtropical and
\end{abstract}

Received: 2019-10-14 Accepted: 2019-12-18

Foundation: National Natural Science Foundation of China, No.41871350; Scientific and Technological Basic Resources Survey Project, No.2017FY100900

Author: Yao Yonghui (1975-), PhD and Associate Professor, specialized in GIS/RS application and mountain environment. E-mail: yaoyh@1reis.ac.cn 
warm temperate zones in China by comprehensively considering the vegetation-climate indicators. Additionally, the boundary between subtropical and warm temperate zones in Qinling-Daba Mountains should be a transitional zone consisting of the boundaries of coniferous forests, broad-leaved forests and shrubs between subtropical and warm temperate zones. The results provide a scientific basis for the selection of delimitation index of subtropical and warm temperate zones.

Keywords: Qinling-Daba Mountains; North-South transitional zone; Pinus tabulaeformis forest; Pinus massoniana forest; climate; subtropical zone; warm temperate zone

\section{Introduction}

The Qinling Mountains is not only the geographical boundary between North and South China, but also the boundary between subtropical and warm temperate zones in China. Liu (1934) pointed out that the south of Qinling Mountains belonged to the southern plant territory and its southeast was bounded by Funiu Mountain and Huaihe River in the study of plant geography in northern and western China. This viewpoint has become the basis of plant regionalization in northern and western China. Zhu (1958) proposed that the Huaihe River-Qinling Mountains-Bailongjiang River should be the northern boundary of subtropical zone in China by indicators of the $>10^{\circ} \mathrm{C}$ accumulated temperature of $4500-8000^{\circ} \mathrm{C}$, the coldest month temperature of $2-16^{\circ} \mathrm{C}$, and the frost-free period of $240-260$ days. This northern boundary of subtropical zone accords with the grain yield dividing line of $500 \mathrm{~kg}$ and $800 \mathrm{~kg}$ per $\mathrm{mu}(=0.0667 \mathrm{ha})$ in the national agricultural development program at that time, and it is also close to the northern boundary of double cropping in one year and the boundary of paddy fields in the south and dry farming in the north for traditional agriculture in China (Mao, 1958). It also reflects the geo-ecological phenomena that the orange in the south of Huaihe River is orange, but bitter than in the north of Huaihe River.

After that this boundary has become the major basis for the division of bioclimatic zoning and geographical pattern in China. However, due to the complexity, transition and heterogeneity of the transitional zone, as well as the differences in the demarcation methods and indicators, and research purposes, there are controversies on the specific location of the North-South geo-ecological boundary in academic world. On the one hand, the Qinling Mountains is long and huge with overlapping peaks and barriers, its north slope is short and steep with deepening rivers and canyons, but its south slope is relatively long and gentle with many mountains and intermountain basins from east to west (Ni et al., 1992); moreover, the north-south span of Qinling-Daba Mountains is nearly 200-300 km wide and the east-west span is about $1000 \mathrm{~km}$ long, all of which resulted in different opinions on the specific location of the boundary. On the other hand, in different research fields, different demarcation methods and indicators with different purposes were adopted and then there were different locations for the boundary. There are normally three locations for the boundary of the north and south China (Kang et al., 2007): the north slope of Qinling Mountains (Hou, 1963, 1964), the main ridgeline of Qinling Mountains (CNRCAS, 1960; Liu, 1981; CVMEC, 1980; 2001), and the south slope of Qinling Mountains at the altitude of $1000 \mathrm{~m}$ (Zhang et al., 1963; Zhang et al., 1979; Lei, 1999; Kang et al., 2007; Wang, 2010). Additionally, some research suggested that the Qinling Mountains was not the boundary of the northern sub- 
tropical zone and the warm temperate zone in China, but should be the boundary of warm temperate zone and temperate zone (Ying et al., 1990; Fang, 1991; Fu et al., 1992; Fang, 2001; Ying et al., 2011).

Besides the differences in the demarcation methods, indicators and research purposes, the lack of data and technology in the past caused the limitations of the selected delimitation indicators. Moreover, most of the research on Qinling-Daba Mountains in the past focused on Qinling Mountains in Shaanxi province, which led to the problems of "fragmentation", "localization", and the lack of unified deep understanding for the characteristics, structure and mechanism of Qinling-Daba Mountains. In addition, the biodiversity of Qinling-Daba Mountains is very complex and heterogeneous (Ying et al., 2001), but there is currently a lack of understanding of it.

Under the background of big data in nowadays, integrated analysis of vegetation distribution data and climatic data, soil, landscape and so on, can deeply understand the characteristics of the Qinling-Daba Mountains, the North-South transitional zone. Therefore, based on 1:1,000,000 vegetation type map of China, SRTM topographic data and climate data (temperature and precipitation), this paper analyzed the spatial distribution of Pinus massoniana forest in the southern subtropical zone and Pinus tabulaeformis forest in the northern temperate zone, and the climatic conditions at their boundary with climate indexes of annual precipitation, and the coldest month (January), the warmest month (July), the annual mean temperatures. The purpose of this paper is to further reveal the importance and role of Qinling-Daba Mountains in China's geo-ecological pattern and discuss the delimitation of the boundary of subtropical and warm temperate zones.

\section{Study area}

The Qinling-Daba Mountains running through the central part of China in the east-west direction plays an important role in China's geo-ecological pattern, which is also known as the North-South transitional zone of China (Figure 1). The Qinling-Daba Mountains mentioned in this paper are mainly composed of Qinling Mountains and Daba Mountains, as well as the low hills in western Henan, the middle and low mountains, the hilly areas in northwest Hubei, and Taizi Mountain, Dieshan Mountain, Minshan Mountain and Longmen Mountain in the west, spanning six provinces and cities such as Shaanxi, Gansu, Sichuan, Chongqing, Hubei and Henan (DGSNU, 1989). The north-south span of the Qinling-Daba Mountains is nearly 200-300 km wide and the east-west span from Diebu Mountain in Gansu province to the Shennongjia Mountain in Hubei province is about $1000 \mathrm{~km}$ long, and its total area is about $300,000 \mathrm{~km}^{2}$. It is affected by both continental and monsoon climate due to locating in mid-latitude region. The Qinling Mountains shields the cold air from the north to the south and blocks the warm-wet air from the southeast to the north (Ying et al., 1990). Thus the climate conditions on the north and south slopes of the Qinling Mountains are quite different. At the meantime, the Qinling-Daba Mountains is an important ecological corridor for the migration of organisms from east to west and from north to south in China and its species distribution is characterized by significant diversity, complexity and transition (Wurster et al., 2014; Caplat et al., 2016). 


\section{Data and methods}

\subsection{Data sources}

(1) Spatial distribution data of Pinus tabulaeformis and Pinus massoniana forests: It was extracted from the 1:1,000,000 Chinese vegetation map (CVMEC, 2000). This data includes the distribution extent, area and type of the two forests. It was mainly used to analyze the spatial distribution pattern of the typical subtropical coniferous forests and the typical warm temperate coniferous forests in the Qinling-Daba Mountains and to explore their boundary.

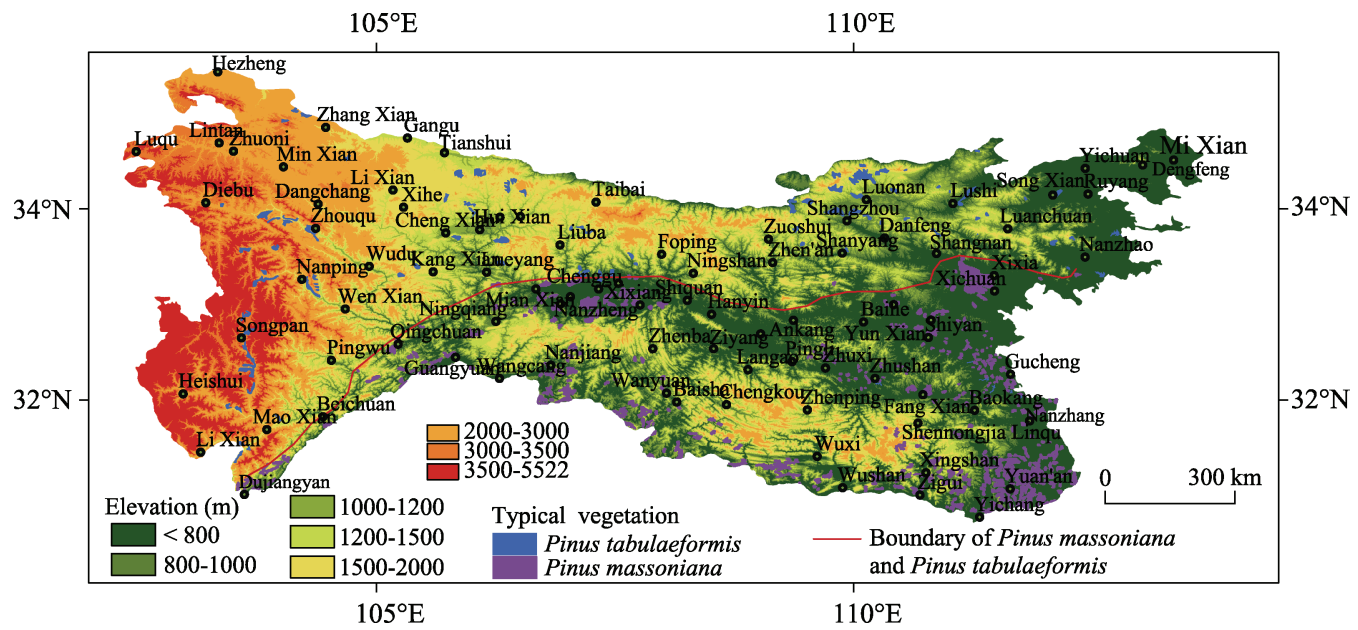

Figure 1 Topographic map of Qinling-Daba Mountains and the spatial distribution of Pinus massoniana and Pinus tabulaeformis forests

(2) Climate data: The climate data includes temperature and precipitation data with a spatial resolution of approximately $1 \mathrm{~km}^{2}$ (downloaded from the website of http://www.worldclim.org/). It was generated by global meteorological station data using the Auspline interpolation method, including monthly temperature, monthly precipitation, annual average temperature and annual precipitation data (Hijmans et al., 2005). This data was used to analyze the spatial pattern of temperature and precipitation in Qinling-Daba Mountains and to extract climate indicators at the boundary of Pinus tabulaeus and Pinus massoniana forests.

(3) Digital Elevation Model (DEM): The SRTM DEM data were derived from Consortium for Spatial Information (CGIAR-CSI) with a spatial resolution of $90 \mathrm{~m}$. All of this data was generated from a seamless dataset. SRTM DEM data was mainly used to analyze the distribution height of Pinus tabulaeus and Pinus massoniana forests.

\subsection{Study methods}

Pinus tabulaeformis forest is a representative coniferous forest in temperate zone of North China. The southwestern boundary of Pinus tabulaeformis forest is located at an altitude of 1000-1600 m in Qinling-Daba Mountains. Pinus massoniana forest is one of the typical representative forests in the humid subtropical zone of southeastern China, and it is widely distributed in the subtropical region. The northern boundary of Pinus massoniana forest is along the Qinling-Funiu Mountain-Huaihe River, which is connected with Pinus tabulaeformis forest in the warm temperate zone. Normally, Pinus massoniana forest is distributed 
in the south slope of the Qinling-Daba Mountains at an altitude of less than $1000 \mathrm{~m}$. A number of studies have indicated that the distribution areas of Pinus tabulaeformis and Pinus massoniana forests overlapped in the Qinling-Daba Mountains. However, the specific locations of the boundary between Pinus tabulaeformis and Pinus massoniana forests and the hydrothermal conditions of the boundary have not been analyzed in details.

In order to reveal the characteristics of the North-South transitional zone and identify the location of the boundary between subtropical and warm temperate zones in China, we selected the two forests of Pinus massoniana and Pinus tabulaeformis respectively representing the coniferous vegetation in subtropical zone of southern China and temperate zone of northern China as objects for further analysis. Firstly, this paper obtained the spatial distribution extents and altitude information of Pinus massoniana and Pinus tabulaeformis forests by overlapping the spatial distribution map of the two types of forests with SRTM DEM data (Figure 1). Secondly, for the purpose of identifying the influence of climatic conditions on the spatial distributions of the two types of forests in Qinling-Daba Mountains, the spatial variation of hydrothermal conditions (annual precipitation, annual average temperature, the coldest month (January) temperature and the warmest month (July) temperature) in Qinling-Daba Mountains have been carefully analyzed. Based on SRTM DEM data and climate data, annual precipitation, annual average temperature, the coldest month (January) temperature and the warmest month (July) temperature were extracted and analyzed (Figures 2 and 3). On the basis of the above analysis, the profiles of temperature and precipitation along the boundary between Pinus massoniana forest and Pinus tabulaeformis forest (Figure 4) were made, and the climatic indexes at the boundary were obtained (Table 1), which should be represented the climatic indexes of the transitional zone of subtropical and warm temperate coniferous forests in Qinling-Daba Mountains.

\section{Results and analysis}

\subsection{Spatial distribution characteristics of Pinus massoniana and Pinus tabulaeformis forests in Qinling-Daba Mountains}

The spatial distributions of Pinus massoniana and Pinus tabulaeformis forests in the Qinling-Daba Mountains have obvious regional differentiation and it is significantly affected by the landform, especially the altitude (Figure 1). Pinus massoniana forest is mainly distributed in the southern part of Qinling-Daba Mountains at an altitude below $1000 \mathrm{~m}$, while Pinus tabulaeformis forest is mainly distributed in the northern part of Qinling-Daba Mountains at an altitude above $1000 \mathrm{~m}$. The boundary between them is located along the line of Nanzhao-Shangnan-Yangxian-Luoyang-Qingchuan from east to west (Figure 1). It gradually inclines from east to southwest, the eastern part of the boundary is nearly at the latitude of $33.45^{\circ} \mathrm{N}$, the south slope of Funiu Mountain at the altitude below $1000 \mathrm{~m}$; the middle part of the boundary is located at the northern edge of the Hanzhong Basin with a latitude of $33.28^{\circ} \mathrm{N}$; The western part of the boundary is inclined to southwest and edged by the mountains at an altitude below $1200 \mathrm{~m}$ in the west of Sichuan. In other words, the boundary between them is located at the south slope of Qinling Mountains (including Funiu Mountain) at an altitude below 1000-1200 $\mathrm{m}$. The topography of Qinling-Daba Mountains is gradually increasing from east to west and the hydrothermal conditions also changes with the the to- 
pography, which is why the boundary is inclined from east to southwest.

\subsection{The influence of climate on the spatial distributions of Pinus massoniana and Pinus tabulaeformis forests in Qinling-Daba Mountains}

The spatial distribution of annual precipitation in the Qinling-Daba Mountains is shown in Figure 2. The distributions of Pinus massoniana and Pinus tabulaeformis forests show a close relationship with precipitation in Qinling-Daba Mountains. The annual precipitation gradually decreases from south to north and northwest in the study area. In the northwest, northeast of the study area and the north slope of Qinling Mountains, the annual precipitation is about $400 \mathrm{~mm}$ to $800 \mathrm{~mm}$. In Hanzhong Basin and the south of Hanshui Valley, the annual precipitation is mostly above $900 \mathrm{~mm}$. The $800-\mathrm{mm}$ precipitation isoline in the east of Qinling-Daba Mountains can reach Funiu Mountain, Shangnan-Xichuan county, Qixian and Shanyin counties; in the central part of the Qinling-Daba Mountains it is located on the north slope of the Qinling Mountains; in the western part of Qinling-Daba Mountains it is spread along the direction of northeast to southwest, near the line along the counties of Taibai-Liuba-Qingchuan-Pingwu (Figure 2). Corresponding to the annual precipitation, Pinus tabulaeformis forest is mainly distributed in the areas where the annual precipitation is less than $800 \mathrm{~mm}$, while Pinus massoniana forest is mainly distributed in areas where the annual precipitation is greater than $800 \mathrm{~mm}$.

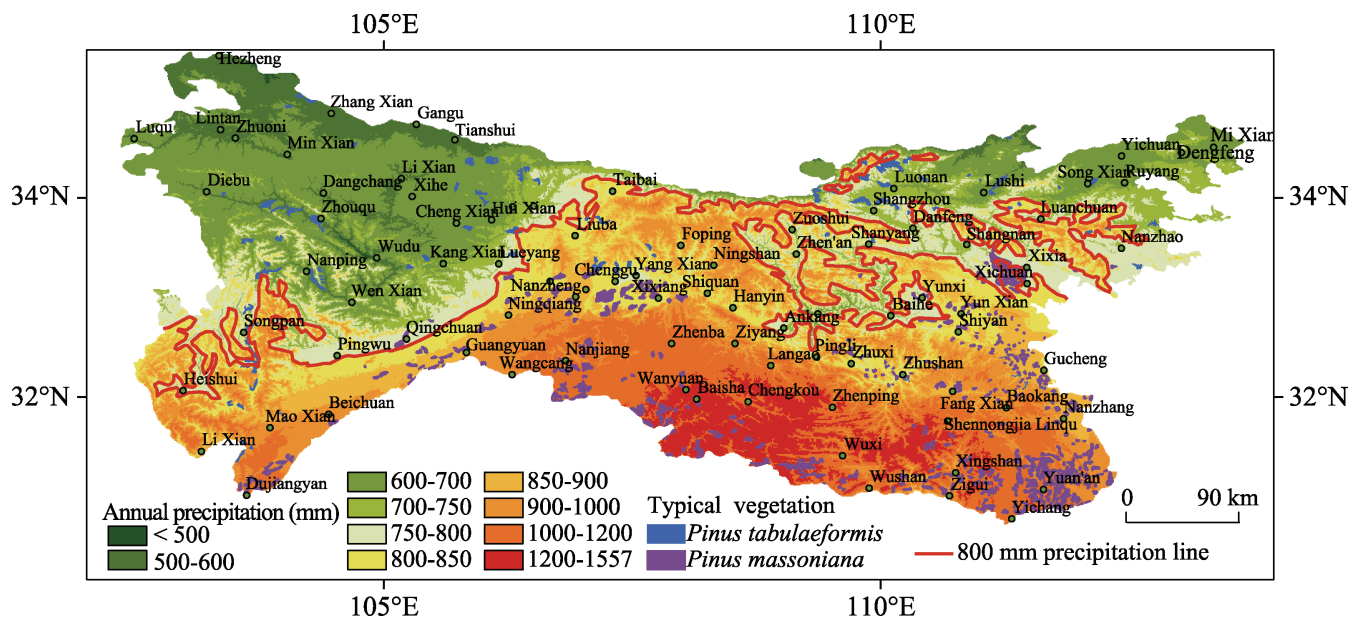

Figure 2 Spatial distribution of annual precipitation in Qinling-Daba Mountains

Similarly, the distributions of Pinus massoniana and Pinus tabulaeformis forests are also closely correlated with the coldest month average temperature, the warmest month average temperature and the annual average temperature in Qinling-Daba Mountains. Firstly, the coldest month (January) average temperature in the north of Qinling Mountains is lower than $0^{\circ} \mathrm{C}$ and it is above $0^{\circ} \mathrm{C}$ on the south slope of Qinling Mountains and its south areas (except for Micangshan Mountain, Daba Mountain and Shennongjia Moutain). In other words, the coldest month (January) average temperature in the areas south to the line of Nanzhao-Xixia-Shangnan-Yunxian in the east range of Qinling-Daba Mountains, south to the line of Xunyang-Zhenan-Ningshan-Yangxian-Liuba in the middle range of Qinling-Daba Mountains and south to the line of Chengxian-Wudu-Wenxian-Pingwu in the west range of 
Qinling-Daba Mountains are above $0^{\circ} \mathrm{C}$. According to the correlation between the distribution of the two forests and the average temperature in January, Pinus massoniana forest is completely distributed in the region with the coldest month temperature above $0^{\circ} \mathrm{C}$ except for Shennongjia Mountain, while Pinus tabulaeformis forest is fully distributed in the region with the temperature below $0^{\circ} \mathrm{C}$ in January (Figure $3 \mathrm{a}$ ).

Secondly, the warmest month (July) average temperature in the Qinling-Daba Mountains (except for some high mountains in the west) is above $10^{\circ} \mathrm{C}$. And it is basically above $25^{\circ} \mathrm{C}$ at an altitude below $1000 \mathrm{~m}$. Correspondingly, Pinus massoniana forest is mainly distributed in the area with the warmest month average temperature above $25^{\circ} \mathrm{C}$, while Pinus tabulaeformis forest is mainly distributed in the area with the temperature below $24^{\circ} \mathrm{C}$ (Figure $3 \mathrm{~b}$ ).

Finally, according to the spatial distribution pattern of annual average temperature, except for the west Qinling-Daba Mountains and the mountains with altitude above $2000 \mathrm{~m}$ such as Daba Mountain and Shennongjia Mountain, the annual average temperature in most areas of Qinling-Daba Mountains is above $10^{\circ} \mathrm{C}$. From west to east and south to the line of Pingwu-Qingchuan-Mianxian-Yangxian (north edge of Hanzhong Basin)-Shiquan-XunyangYunxian-Xixia-Nanzhao, the annual average temperature is above $13^{\circ} \mathrm{C}$. Importantly, Pinus massoniana forest is mainly distributed in the areas with the annual average temperature above $13^{\circ} \mathrm{C}$. On the contrary, Pinus tabulaeformis forest is mostly distributed in areas with the annual average temperature below $13^{\circ} \mathrm{C}$ (Figure $3 \mathrm{c}$ ).

\subsection{Climatic characteristics at the boundary between Pinus massoniana and Pinus tabulaeformis forests in Qinling-Daba Mountains}

In order to further understand the influence of the climate on the distribution of Pinus massoniana forest and Pinus tabulaeformis forest, the profiles of temperature (January average temperature, July average temperature and annual average temperature) and annual precipitation (Figure 4) were made along the boundary between them (Figure 1), and the climatic indexes on the profiles were analyzed statistically (Table 1), which provides a scientific basis for identification of the coniferous forest transitional zone between subtropical zone and warm temperate zone in Qinling-Daba Mountains. The results show that the temperature and annual precipitation indicators at the boundary are relatively stable. Firstly, the average temperature of the coldest month (January) is about $2-4^{\circ} \mathrm{C}$ in the west of the profile (west of $106^{\circ} \mathrm{E}$ ) and $0-2^{\circ} \mathrm{C}$ in the middle and east of the profile (east of $106^{\circ} \mathrm{E}$ ); secondly, the average temperature of the warmest month (July) is $22-24^{\circ} \mathrm{C}$ in the west of the profile (west of $105^{\circ} \mathrm{E}$ ) and $24-26^{\circ} \mathrm{C}$ in the middle and east of the profile (east of $105^{\circ} \mathrm{E}$ ); thirdly, the annual average temperature at the profile is basically between $12^{\circ} \mathrm{C}$ and $14^{\circ} \mathrm{C}$. In addition, the annual precipitation is $800-1000 \mathrm{~mm}$ in the west of the profile (west of $105^{\circ} \mathrm{E}$ ), while it is $750-900 \mathrm{~mm}$ in the middle and east of the profile (east of $105^{\circ} \mathrm{E}$ ).

\section{Conclusions and discussion}

\subsection{Discussion}

(1) Indicators for delimitation of subtropical and warm temperate boundary in Qinling- 

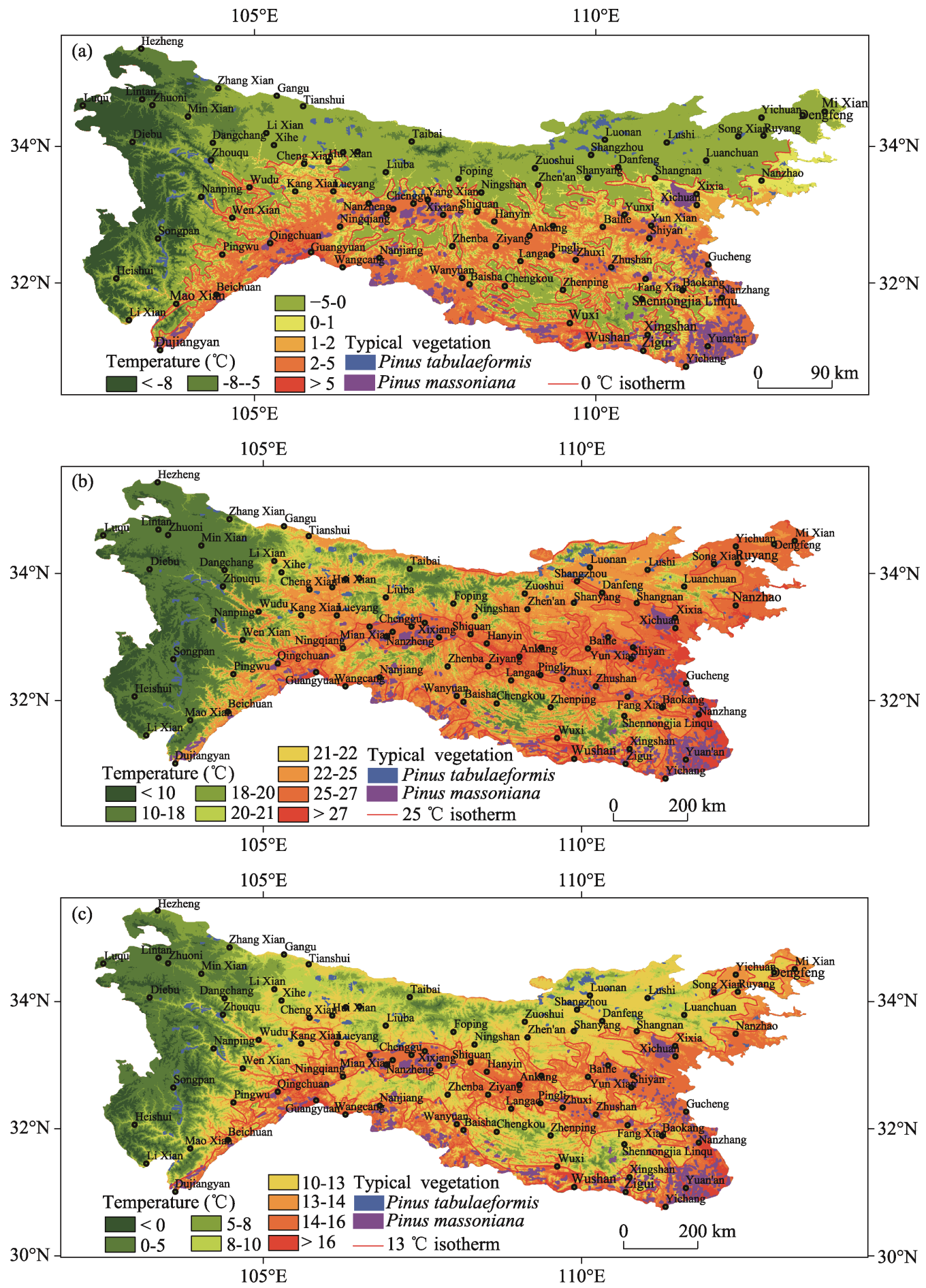

Figure 3 Temperature distribution of Qinling-Daba Mountains (a. January average temperature; b. July average temperature; c. annual average temperature)

\section{Daba Mountains}

In previous studies, climate indicators such as the accumulated temperature above $10^{\circ} \mathrm{C}$, 
Table 1 Temperature and precipitation at the boundary of Pinus tabulaeformis and Pinus massoniana forests

\begin{tabular}{cccc}
\hline $\begin{array}{c}\text { Climatic } \\
\text { indicator }\end{array}$ & $\begin{array}{c}\text { The coldest month (January) } \\
\text { average temperature }\left({ }^{\circ} \mathrm{C}\right)\end{array}$ & $\begin{array}{c}\text { The warmest month (July) } \\
\text { average temperature }\left({ }^{\circ} \mathrm{C}\right)\end{array}$ & $\begin{array}{c}\text { Annual average } \\
\text { temperature }\left({ }^{\circ} \mathrm{C}\right)\end{array}$ \\
\hline Value & $0-4$ & $22-26$ & $\begin{array}{c}\text { Annual precipita- } \\
\text { tion }(\text { mm })\end{array}$ \\
\hline
\end{tabular}

days with an average daily temperature above $10{ }^{\circ} \mathrm{C}$, warm index (WI) and so on were usually used to delimitate the boundary between subtropical zone and warm temperate zone (Zheng et al., 2008; Zheng et al., 2010; Zheng et al., 2010; Chen, 1982). Besides the climate indicators, plant species and plant structure, floristic dominant groups, soil were also used to delimitate the boundary (Kang et al., 2007;

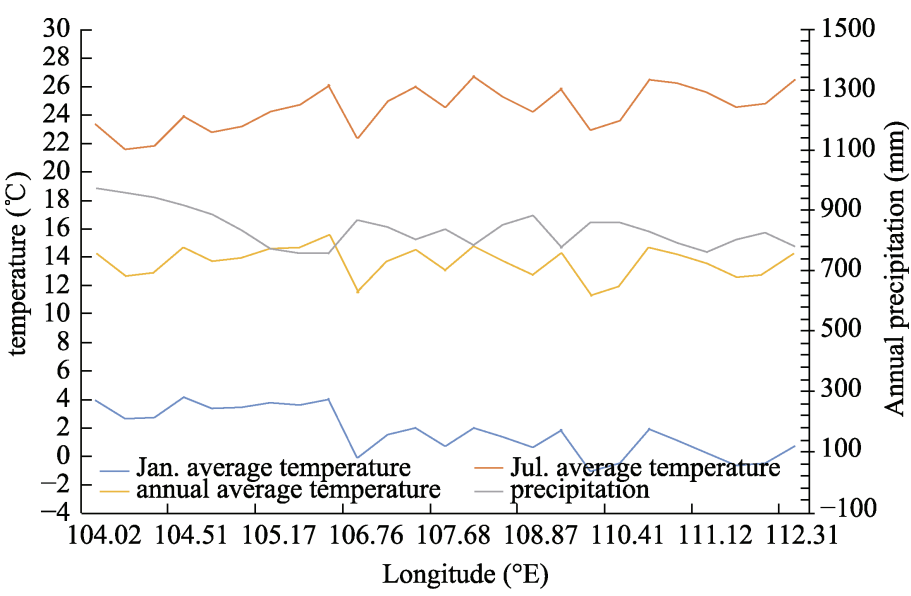

Figure 4 Temperature and precipitation profiles at the boundary between Pinus massoniana and Pinus tabulaeformis forests Zhang et al., 1963; Zhang et al., 1979; Lei et al., 1999; Wang et al., 2010). Due to different indicators adopted in different research fields, the specific locations of the boundary were quite different, too. Focusing on the relationship between vegetation and climate, appropriate vegetation-climate indicators should reflect the change of land surface pattern more comprehensively than simply considering climate factors or vegetation factors. The results of this paper also show that there is a clear geographical boundary between the subtropical typical coniferous forest (Pinus massoniana forest) and the temperate typical coniferous forest (Pinus tabulaeformis forest) in the Qinling-Daba Mountains and the climate indicators at this boundary (annual precipitation, annual average temperature, the coldest month average temperature and the warmest month average temperature) are also very stable. That is to say, adopting representative vegetation-climate indicators in subtropical and warm temperate zones can more scientifically delimitate the boundary of climate zones.

(2) The location of the boundary between subtropical zone and warm temperate zone in Qinling-Daba Mountains

As above stated, there are normally three locations for the boundary of north and south China (Kang et al., 2007): the north slope of Qinling Mountains (Hou, 1963, 1964), the main ridgeline of Qinling Mountains (CNRCAS, 1960; Liu, 1981; CVMEC, 1980; 2001), and the south slope of Qinling Mountains at the altitude of $1000 \mathrm{~m}$ (Kang et al., 2007; Zhang et al., 1963; Zhang et al., 1979; Lei, 1999; Wang, 2010). In this paper, the boundary of typical coniferous forests between subtropical zone and warm temperate zone is located at the south slope of Qinling Mountains below the altitude of 1000-1200 m, which is coincided with the viewpoint of the boundary located at the altitude of $1000 \mathrm{~m}$ of the south slope of Qinling Mountains. However, due to different vegetation types with different requirements for climatic conditions, their spatial distributions are also different, for example, the distribution of 
broad-leaved forests is significantly different from that of coniferous forests. Therefore, the boundary between the subtropical typical coniferous forest (Pinus massoniana forest) and the temperate typical coniferous forest (Pinus tabulaeformis forest) in the Qinling-Daba Mountains does not represent the boundary between the subtropical zone and the warm temperate zone. In other words, when identifying the boundary between subtropical zone and the warm temperate zone, it is necessary to consider the spatial distribution and boundaries of coniferous forests, broad-leaved forests, shrubs and even herbaceous vegetation in different climatic zones. Therefore, the boundary of subtropical zone and warm temperate zone should be a transitional zone composed of the boundaries of coniferous forests, broad-leaved forests and shrubs between subtropical and warm temperate zones.

\subsection{Conclusions}

(1) The boundary of Pinus massoniana forest and Pinus tabulaeformis forest and the climate indictors of the boundary can be used as one of the vegetation-climate indexes for the delimitation of subtropical zone and warm temperate zone. The boundary between subtropical coniferous forest (Pinus massoniana forest) and temperate coniferous forest (Pinus tabulaeformis forest) in Qinling-Daba Mountains is located at the south slope of Qinling Mountains (from the south slope of Funiu Mountain to the northern edge of Hanzhong Basin) at an altitude of 1000-1200 m. The climate indicators at the boundary of the two conifer forests are very stable: the annual precipitation is about $750-1000 \mathrm{~mm}$, the annual average temperature is between $12-14^{\circ} \mathrm{C}$, the coldest month temperature is about $0-4^{\circ} \mathrm{C}$, and the warmest month temperature is about $22-26^{\circ} \mathrm{C}$.

(2) It is important to comprehensively consider the vegetation-climate indicators for identifying the boundary between the subtropical and warm temperate zones in the Qinling-Daba Mountains, which can more scientifically identify the location of the boundary between the climate zones and reveal the characteristics of the transitional zone. Vegetation-climate indicators should include coniferous forest-climate indicators, broad-leaved forest-climate indicators, and shrubs-climate indicators, and so on. Additionally, the boundary of subtropical zone and warm temperate zone in Qinling-Daba Mountains should be a transitional zone composed of the boundaries of coniferous forests, broad-leaved forests and shrubs between subtropical and warm temperate zones.

\section{References}

Caplat P, Edelaar P, Dudaniec R Y et al., 2016. Looking beyond the mountain, dispersal barriers in a changing world. Frontiers in Ecology and the Environment, 14: 261-268.

Chen Xianji, 1982. A new approach to the climate division of China. Acta Meteorologica Sinica, 40(1): 35-48. (in Chinese)

Chinese Vegetation Map Editorial Committee (CVMEC), 1980. Vegetation and Vegetation Regionalization Map in China. Beijing: Science Press. (in Chinese)

Chinese Vegetation Map Editorial Committee, CAS (CVMEC), 2001. Vegetation Atlas of China (1:1,000,000). Beijing: Science Press. (in Chinese)

Committee of Natural Regionalization in CAS (CNRCAS), 1960. Regionalization of Chinese Vegetation (First Draft). Beijing: Science Press.

Department of Geography, Shaanxi Normal University (DGSNU), 1989. Geomorphological Map Description of 
Qinling-Daba Mountains in China. Xi'an: Shaanxi People's Publishing House. (in Chinese)

Fang Jingyun, 1991. Eco-climatological analysis of the forest zones in China. Acta Ecologica Sinica, 11(4): 377-387. (in Chinese)

Fang Jingyun, 2001. Re-discussion about the forest vegetation zonation in Eastern China. Acta Botanica Sinica, 43(5): 522-533. (in Chinese)

Fu Zhijun, Guo Junli, 1992. The characters of community on the vegetation of the Taibai Mountain in the Qinling. Journal of Baoji Normal University, (1): 18-25. (in Chinese)

Hijmans R J, Cameron S E, Parra J L et al., 2005. Very high resolution interpolated climate surfaces for global land areas. International Journal of Climatology, 25(15): 1965-1978.

Hou Xueyu, 1963. Discussion on controversial issues in previous vegetation zoning projects in China (II). Acta Phytoecologica et Geobotanica Sinica, 1(1/2): 1-30. (in Chinese)

Hou Xueyu, 1964. Discussion about the principals, foundations and systematic units of Chinese vegetation regionalization. Acta Phytoecologica et Geobotanica Sinica, 2(2): 153-179. (in Chinese)

Kang Muyi, Zhu Yuan, 2007. Discussion and analysis on the geo-ecological boundary in Qinling Range. Acta Ecologica Sinica, 27(7): 2774-2784. (in Chinese)

Lei Mingde, 1999. Vegetation of Shaanxi. Beijing: Science Press. (in Chinese)

Liu Huaxun, 1981. The vertical zonation of mountain vegetation in China. Acta Geographica Sinica, 36(3): 267-279. (in Chinese)

Liu Shene, 1934. Botanical geography in north and west of China. Contributions from the Institute of Botany, National Academy of Peiping, 2(9): 423-464. (in Chinese)

Mao Hanying, 1958. Agricultural boundary survey of Qinling Mountain and Huaihe River areas. (in Chinese)

Ni Shaoxiang, Ding Dengshan, 1992. Scenic View of China's Famous Mountains. Nanjing: Jiangsu Education Press, 167-176. (in Chinese)

Wang Jinglan, Liu Quanru, Meng Shiyong et al., 2010. Division of the geo-ecological boundary in Qinling Mountain Range based on the composition and geographical elements of its Pteridophyta flora. Geographical Research, 29(9): 1629-1638. (in Chinese)

Wurster C M, Bird M I, 2014. Barriers and bridges, early human dispersals in equatorial SE Asia. Geological Society London Special Publications. doi: 10.1144/SP411.2.

Ying Junsheng, Chen Mengling, 2011. Plant Geography of China. Shanghai: Shanghai Science and Technology Press. (in Chinese)

Ying Junsheng, Li Yunfeng, Guo Qinfeng et al., 1990. Observations on the flora and vegetation of Taibai Shan, Qinling Mountain Range. Acta Phytotaxonomica Sinica, 28(4): 261-293. (in Chinese)

Zhang Xuezhong, Zhang Zhiying, 1979. A preliminary discussion on the northern boundary of subtropical zone in China based on the distribution of broad-leaf woody evergreens on the Qinling Mountain. Acta Geographica Sinica, 34(4): 342-352. (in Chinese)

Zhang Zhenwan, Cui Youwen, 1963. Draft of vegetation regionalization in Qinling Region. Acta Phytoecologica et Geobotanica Sinica, 1(1/2): 161-162. (in Chinese)

Zheng Dawei, Sun Zhongfu, 2010. Discussion on scientificalness problem of accumulated temperature and its unit. Chinese Journal of Agrometeorology, 31(2): 165-169. (in Chinese)

Zheng Du, Yang Qinye, Wu Shaohong et al., 2008. Study on the Eco-geographical Region System of China. Beijing: The Commercial Press. (in Chinese)

Zheng Jingyun, Yin Yunhe, Li Bingyuan, 2010. A new scheme for climate regionalization in China. Acta Geographica Sinica, 65(1): 3-12. (in Chinese)

Zhu Kezhen, 1958. Subtropics of China. Chinese Science Bulletin, 17: 524-528. (in Chinese) 